DOI 10.37882/2223-2982.2021.11.21

\title{
ПРИМЕНЕНИЕ ПЛАВАНИЯ И КОРРИГИРУЮЩЕЙ ГИМНАСТИКИ СТУДЕНТАМИ СПЕЦИАЛЬНОГО МЕДИЦИНСКОГО ОТДЕЛЕНИЯ С ЗАБОЛЕВАНИЯМИ ОПОРНО-ДВИГАТЕЛЬНОГО АППАРАТА
}

\section{THE APPLICATION OF SWIMMING AND CORRECTIVE GYMNASTICS BY STUDENTS A SPECIAL MEDICAL DEPARTMENT WITH DISEASES OF THE MUSCULOUS-MOTOR EQUIPMENT \\ I. Mosin \\ I. Mosina \\ M. Esaulov \\ E. Petrushova}

Summary: Revealed a positive transfer from specialized corrective exercises, to the development of basic physical qualities, as well as to health promotion, the formation of a healthy lifestyle, and is the main component in teaching students of a special medical department with diseases of the musculoskeletal system and posture disorders in a technical university according to the program «Physical culture». Nonstandard approaches have been found for health-improving classes with students of a special medical group in a technical university, with diseases of the musculoskeletal system and impaired posture, they become more in demand and relevant in connection with a sedentary image among students of a technical university. An analysis is presented of the use of specialized exercises in corrective gymnastics, which allows students of a special medical group to improve the indicators of flexibility and mobility, a method of recreational swimming with posture diseases has been developed, which allows to relax tense spasmodic muscles of the back and relieve static tension from the spine from monotonous sitting work, describes the features of their use in a special branch. Experimental data were obtained for improving the flexibility and mobility of the musculoskeletal system from a complex of specialized corrective exercises. Improved indicators of the cardiovascular and respiratory systems, from classes in the swimming pool. The positive effect of specialized corrective exercises on the body of students is shown, and the maximum effect on their well-being and physical performance is traced, it reduces fatigue during study.

Keywords: optimal load, flexibility in joints, scoliosis, recreational swimming, specialized corrective exercises.

\section{Мосин Игорь Васильевич}

к.п.н., дочент, Национальный исследовательский ядерный университет «МИФИ»

mosin59@mail.ru

Мосина Ирина Николаевна

дочент, Национальный исследовательский ядерный университет «МИФИ»

trenermosina@yandex.ru

Есаулов Михаил Николаевич

К.т.н., доцент, Национальный исследовательский ядерный университет «МИФИ»

mesaulov@mail.ru

Петрушова Евгения Игоревна

к.п.н., эксперт, компания РОСТФИТ happymosik@yandex.ru

Аннотация: Выявлен положительный перенос от специализированных корригирующих упражнений, на развитие основных физических качеств, а также, на укрепление здоровья, формирование здорового образа жизни, и является основной составляющей в обучении студентов специального медицинского отделения с заболеваниями опорно-двигательного аппарата и нарушениями осанки в условиях технического вуза по программе «Физическая культура». Найдены нестандартные подходы, для оздоровительных занятий со студентами специальной медицинской группы в условиях технического вуза, с заболеваниями опорно-двигательного аппарата и нарушением осанки, они становятся более востребованными и актуальными в связи с малоподвижным образом среди студентов технического вуза. Представлен анализ, использования специализированных упражнений корригирующей гимнастики позволяющий студентам специальной медицинской группы улучшить показатели гибкости и подвижности, разработана методика оздоровительного плавания с заболеваниями осанки, позволяющая расслабить напряженные спазмированные мышцы спины и снять статическое напряжение с позвоночника от монотонной сидячей работы, описаны особенности применения их в специальном отделении. Получены экспериментальные данные улучшения показателей гибкости и подвижности опорно-двигательного аппарата от комплекса специализированных корригирующих упражнений. Улучшены показатели сердечно-сосудистой и дыхательной систем, от занятий в плавательном бассейне. Показано положительное воздействие специализированных корригирующих упражнений на организм студентов, и прослеживается максимальный эффект на их самочувствии и физической работоспособности, уменьшает утомляемость, во время учебы.

Ключевые слова: оптимальная нагрузка, гибкость в суставах, сколиоз, оздоровительное плавание, специализированные корригирующие упражнения.

Это следствие того, что нарастающий темп современной жизни требует полной отдачи внутренних ресурсов и сил в процессе учебы. Будущие студенты технических ВУЗов, при подготовке к ЕГЭ в школе, дополнительно занимаются по избранной специальности, что требует настоящее время, у студентов технических вузов, все чаще встречается заболевание опорно-двигательного аппарата $[1,5]$. 
изыскания дополнительного резерва организма, как со стороны нервной, так и сердечно-сосудистой систем $[2,7,8]$. Малоподвижный образ жизни, высокая нагрузка на ЦНС приводит к нарушениям в регуляции обменных процессов организма, в следствие чего, происходят «перебои» в адаптации к стрессу [3]. А это, в свою очередь, ведет к изменению психосоматического состояния молодого неокрепшего организма [8]. При поступлении в ВУЗ такие студенты уже имеют отклонения в состоянии здоровья, и направляются в специальное отделение с нарушениями осанки $[1,4,6]$.

\section{Анализ послеАних публикаций}

В представленных публикациях авторов [1,5,6,8] применение корригирующей гимнастики основном описано в специализированных медучреждениях и не затрагивает систему физического воспитания в условиях технического вуза. Поэтому проблема организации занятий со студентами в специальном отделении, имеющие отклонение в состоянии здоровья с использованием корригирующей гимнастики и оздоровительного плавания локомоторных, весьма значима и недостаточна решена, и мало описана.

\section{Актуальность}

Воспитание основных физических качеств [4], формирование здорового образа жизни, привлечение студентов к регулярным занятиям физической культурой и спортом является наиболее актуальной $[3,11]$. Задача вуза искать новые формы, средства и методы для активизации интереса к занятиям физическими упражнениями $[9,10]$. Применение новых методик для развития физических качеств на занятиях по физической культуре в техническом вузе вносит новизну в обучении и повышает эмоциональный настрой обучающихся $[9,10]$. Особенностью экспериментальной методики является применение специализированных корригирующих упражнений в гимнастическом зале и в плавательном бассейне для студентов специальной медицинской группы. Показано положительное влияние экспериментальной методики, на физическое состояние студентов, улучшающих свои показателе в тесте на гибкость. Оздоровительные занятия со студентами специальной медицинской группы в условиях технического вуза, с заболеваниями опорно-двигательного аппарата и нарушением осанки с каждым годом становятся популярнее. Положительное воздействие специализированных корригирующих упражнений на организм студентов, положительно прослеживается эффект на их самочувствии и физической работоспособности, уменьшает утомляемость, во время учебы. Заболевание опорно-двигательного аппарата у студентов технических вузов все чаще происходит из-за малоподвижного образа жизни $[1,5]$. Большая учебная нагрузка (сидение) 4-6 пар, ока- зывает влияние на формирование осанки у учащихся. Мышцы спины, при такой ежедневной нагрузке теряют свою эластичность и способность эффективно функционировать. Скованность и напряжение в мышцах вызывает их спазм, что в свою очередь ведет к изменению в положении позвоночного столба. Натяжение в сторону спазмированной мышцы, вызывает сколиоз. Известно, что плавание снимает статическое напряжение с мышц позвоночника [4,9], тем самым улучшает их растяжение и улучшает кровообращение. Корригирующая гимнастика, способствует увеличению подвижности в суставах, укрепляет мышечный корсет, снимает напряжение и увеличивает гибкость [2,6]. Поэтому занятия со студентами специальной медицинской группы, с заболеваниями опорно-двигательного, корригирующей гимнастикой и оздоровительным плаванием, в рамках учебной программы по физической культуре, на данный момент недостаточно решены и остается быть весьма актуальной, для укрепления здоровья студентов технического вуза и насущной проблемой.

\section{Шель исследования}

Целью нашего исследования было, показать эффективность предлагаемой нами методики оздоровительного плавания и корригирующей гимнастики и сравнить, какая из предложенных программ в коррекции осанки наиболее действенная.

\section{Задачи исследования:}

- разработать специализированные корригирующие упражнения для занятий студентов специальной медицинской группы в гимнастическом зале и в плавательном бассейне с заболеваниями опорно-двигательного аппарата;

- экспериментально подтвердить эффективность разработанных упражнений на снятие напряжения и улучшение гибкости и подвижности в суставах в условиях педагогического эксперимента.

\section{Организация и методы исследования}

Студенты технического ВУЗа специального медицинского отделения, имеющие нарушения в осанке, в режиме академических занятий физической культурой, 2 раза в неделю посещали занятия. Одна группа студентов - 8 человек, проводила занятия в бассейне на базе МГТУ им. Н.Э. Баумана. Вторая группа студентов - 12 человек, проводила занятия в гимнастическом зале на базе НИЯУ МИФИ в течение семестра.

Для объективного контроля за эффективностью, предлагаемой нами методики, в тестировании студентов специальной медицинской группы, с заболеваниями опорно-двигательного аппарата, мы выбрали тест на гибкость. 
Гибкость - основное физическое качество, которое объективно отражает показатели эластичности мышц.

Студенты выполняли в качестве тестового задания наклон вперед со скамьи. Измерение гибкости проводилось в начале и в конце эксперимента. Наклон на 5 см - «удовлетворительно», на 10 см оценивался как «хорошо», на 15 см - «отлично». Результаты тестирования представлены в табл. 1, и, табл. 2

\section{Методика обучения при использовании спешиализированных упражнений}

В начале занятий обе группы проводили общую разминку 10-15 мин. Группа №1 в бассейне выполняла следующие специализированные упражнения:

1. Плавание на спине «стрелочкой».

Оттолкнитесь от бортика бассейна, примите горизонтальное положение на спине, вытяните руки за головой так, чтобы руки переплелись между собой и образовали натяжение, работайте ногами попеременно. 50-100 м.

2. Плавание на спине, гребок двумя руками.

Оттолкнитесь от бортика, примите горизонтальное положение на спине, вытяните руки за головой, работайте ногами попеременно. Выполните гребок двумя руками к бедру через стороны, слегка сгибая руки в локтях. Скользить 1-2 сек. 50-100 м.

3. Плавание брассом на спине.

Оттолкнитесь от бортика бассейна, примите горизонтальное положение, руки вытяните за головой, работайте ногами способом брасс. Выполните 2-3 толчка ногами, затем 1 гребок руками к бедрам через стороны, 100 м.

4. Плавание смешанным способом.

Упражнение для укрепления мышц поясницы. Оттолкнитесь от бортика бассейна, примите горизонтальное положение на груди, руки вытянуты вперед «стрелкой». Работайте ногами попеременно кролем, выдыхая в воду, руки работают способом брасс, 100 м.

5. Плавание способом кроль на груди.

Упражнение для расслабления мышц грудного отдела. Оттолкнитесь от бортика бассейна, примите горизонтальное положение на груди, руки вытяните вперед. Выполните гребок левой рукой, лечь на правый бок, скользить 1-2 сек, гребок правой рукой лечь на левый бок, скользить 1-2 сек, ноги работают попеременно кролем. Дыхание выполняется под любую из рук. 100 м.

Таблица 1

Тестирования студентов, выполнявших комплекс специализированных упражнений в плавательном бассейне

\begin{tabular}{|c|c|c|c|c|}
\hline \multicolumn{2}{|c|}{ Группа № 1 (плавание) } & Тест №1 (наклон вперед, см) & Тест №2 (наклон вперед, см) & Разница - \\
\hline 1. & Син-ов & $4 \mathrm{~cm}$ & $7 \mathrm{~cm}$ & $+3 \mathrm{~cm}$ \\
\hline 2. & Кон-нов & $3 \mathrm{~cm}$ & $6 \mathrm{~cm}$ & $+3 \mathrm{~cm}$ \\
\hline 3. & Вас-ев & $3 \mathrm{~cm}$ & $5 \mathrm{~cm}$ & $+2 \mathrm{~cm}$ \\
\hline 4. & Ино-ев & $4 \mathrm{~cm}$ & $7 \mathrm{~cm}$ & $+3 \mathrm{~cm}$ \\
\hline 5. & Пров-ов & $5 \mathrm{~cm}$ & $7 \mathrm{~cm}$ & $+2 \mathrm{~cm}$ \\
\hline 6. & Шуш-ев & $4 \mathrm{CM}$ & $6 \mathrm{~cm}$ & $+2 \mathrm{~cm}$ \\
\hline 7. & Про-ов & $3 \mathrm{~cm}$ & $5 \mathrm{~cm}$ & $+2 \mathrm{~cm}$ \\
\hline 8. & Три-ев & $4 \mathrm{~cm}$ & $7 \mathrm{~cm}$ & $+3 \mathrm{~cm}$ \\
\hline
\end{tabular}

Таблица 2

Тестирования студентов выполнявших комплекс специализированных упражнений в гимнастическом зале

\begin{tabular}{|c|c|c|c|c|}
\hline \multicolumn{2}{|c|}{ Группа №2 (гимнастический зал) } & Тест №1 (наклон вперед, см) & Тест №2 (наклон вперед, см) & Разница - \\
\hline 1. & Мур-ов & $5 \mathrm{~cm}$ & $9 \mathrm{~cm}$ & $+4 \mathrm{~cm}$ \\
\hline 2. & Ис-ев & $3 \mathrm{~cm}$ & $7 \mathrm{~cm}$ & $+4 \mathrm{~cm}$ \\
\hline 3. & Пре-ин & $2 \mathrm{~cm}$ & $5 \mathrm{~cm}$ & $+3 \mathrm{~cm}$ \\
\hline 4. & Фон-ев & $6 \mathrm{~cm}$ & $9 \mathrm{~cm}$ & $+3 \mathrm{~cm}$ \\
\hline 5. & Кре-ов & $4 \mathrm{~cm}$ & $9 \mathrm{~cm}$ & $+5 \mathrm{~cm}$ \\
\hline 6. & Блю-ев & $3 \mathrm{~cm}$ & $8 \mathrm{~cm}$ & $+5 \mathrm{~cm}$ \\
\hline 7. & Фео-ов & $5 \mathrm{~cm}$ & $9 \mathrm{~cm}$ & $+4 \mathrm{~cm}$ \\
\hline 8. & Бег-ов & $3 \mathrm{~cm}$ & $8 \mathrm{~cm}$ & $+5 \mathrm{~cm}$ \\
\hline 9 & Сын-ев & $2 \mathrm{~cm}$ & $8 \mathrm{~cm}$ & $+4 \mathrm{~cm}$ \\
\hline 10 & Вел-ов & $4 \mathrm{~cm}$ & $12 \mathrm{~cm}$ & $+4 \mathrm{~cm}$ \\
\hline 11 & Сав-ен & $7 \mathrm{~cm}$ & $10 \mathrm{~cm}$ & $+5 \mathrm{~cm}$ \\
\hline 12 & При-щев & $6 \mathrm{~cm}$ & $+4 \mathrm{~cm}$ \\
\hline
\end{tabular}


6. Плавание способом брасс.

Оттолкнитесь от бортика бассейна, примите горизонтальное положение, руки вытяните вперед, выполните толчок ногами, соедините вместе и скользите 2 сек. Выполните гребок руками перед собой, вдохните. Погружая голову в воду, снова выполните толчок ногами, и проскользите $100 \mathrm{M}$.

7. Плавание способом брасс на ногах.

Возьмите плавательную доску, ногами оттолкнитесь от бортика бассейна, примите горизонтальное положение на груди, руки вытянуты вперед, лежат на плавательной доске, толкаемся ногами и скользим 2 сек, 50-100 м.

8. Плавание способом брасс на руках.

Возьмите колобашку, зажмите ее между ног, оттолкнитесь от бортика бассейна, руки вытянуты вперед. Выполните 1-2 гребка руками под водой, а затем гребок с дыханием. 50-100 м.

Общий объем за тренировочное занятие от 600 до $800 \mathrm{~m}$.

Группа №2 в гимнастическом зале выполняла комплекс корригирующей гимнастики:

1. «Сгибание/разгибание в позвоночнике с опорой на колени и кисти рук. И.П. стоя на четвереньках: сделать разгибание в грудном отделе и сгибание в поясничном. 10-15 повторений.

2. И.П. сед на пятках согнувшись руки вперед, переход в положение лежа и обратно 10-15 раз.

3. «Волна» И.П. стоя на четвереньках, сгибая руки прогнуться вперед в грудном отделе и вернуться обратно 10-15 раз.

4. И.П. стоя на четвереньках, мах коленом к груди, мах согнутой ногой назад, прогнуться в поясничном отделе, 10-15 раз на каждую ногу.

5. «Скручивание ногой» И.П. стоя на четвереньках, выполняем перемещение правой ноги за левую, скрестно. Ставим прямую ногу слева и справа от себя 10-15 раз каждой ногой.

6. «Перекаты на спине» И.П. лежа на спине, подбородок к груди, руками обнять колени, спина круглая. Перекаты вперед назад 10-15 раз.

7. И.П. лежа на животе, руки положить под подбородок, поднимаем прямую ногу назад на 30 см от пола. 30 раз каждой ногой.

8. И.П. лежа на животе руки вперед. Попеременно поднимаем левою ногу и правую руку, правую ногу и левую руку 10-15 раз каждой парой.

9. «Коробочка» И.П. лежа на животе. Руками захватить обе стопы, прогнуться максимально назад, И.П. выполнять 10-15 раз.

10. «Сухое плавание» И.П. лежа на животе руки вперед. 1 - левая рука за спину, 2 - правая рука за спину, 3 прогнуться, 4 - руки вперед. Выполнить 10-15 раз.
Все студенты выполнили тест на «удовлетворительно», что естественно для специального медицинского отделения, с нарушением осанки.

\section{Результаты исследования}

В результате проведенного эксперимента мы выявили следующее: все студенты улучшили показатели гибкости в среднем на 3-5 см, наибольший эффект показали студенты занимающиеся в гимнастическом зале 4,5см. Студенты специального медицинского отделения, с заболеваниями ОДА, занимающиеся оздоровительным плаванием и в гимнастическом зале комплексом корригирующих упражнений, значительно улучшили показатели гибкости. Это достоверно показали результаты тестирования на гибкость до эксперимента, и после.

\section{Выводы:}

1. Занятия корригирующей гимнасткой в спортивном зале наиболее эффективна, для коррекции осанки и опорно-двигательного аппарата.

2. Занятия оздоровительным плаванием позволяет получить максимальный результат на расслабление мышц спины и укрепление сердечно-сосудистой и дыхательных систем.

3. Предложенная нами методика специализированных упражнений для улучшения осанки и опорно-двигательного аппарата, как в гимнастическом зале, так и в бассейне со студентами специальной медицинской группы экспериментально подтвердила его эффективность.

4. Мы считаем, что разработанные нами специальные корригирующие упражнения для студентов специальной медицинской группы с заболеваниями опорно-двигательного аппарата, можно рекомендовать для снятия напряжения и улучшения гибкости и подвижности в суставах, а это в свою очередь улучшит состояние здоровья студентов и повысит их работоспособность и уменьшит утомляемость.

\section{Перспективы Аальнейших исследований}

Использование специализированных корригирующих упражнений в гимнастическом зале и в плавательном бассейне, для студентов специальной медицинской группы с заболеваниями опорно-двигательного аппарата и нарушении осанки, в условиях технического вуза, создает предпосылки для занятий не только с этими заболеваниями, но и с избыточным весом, сердечно-сосудистыми заболеваниями, дыхательной недостаточностью. Наши дальнейшие исследования, будут направлены на изучение данной проблемы, будут подобраны и апробированы новые методики работы со студентами, имеющие эти заболевания 


\section{ЛИТЕРАТУРА}

1. Аристакесян В.О., Мандриков В.Б., Мицулина М.П. Динамика физической подготовленности студентов с сочетанными нарушениями функций опорнодвигательного аппарата // Научно-теоретический журнал «Ученые записки». - 2015. - № 1 (119). - С. $21-25$.

2. Бакулина Е.Д. Формирование здорового образа жизни студентов средствами оздоровительной гимнастики. Стратегия инновационного развития России и социальная сплоченность. 11 международный соци альный конгресс. - М., 2011. - С. 39-44.

3. Гогинава С.Е., Щербин Д.В., Коник А.А. Исследование влияния оздоровительного плавания на показатели функциональной тренированности студентов вуза // Известия ТулГУ. Физическая культура. Спорт. 2019.- С.22-26.

4. Дрогомерецкий В.В. Коррекция нарушений осанки у студентов средствами оздоровительного плавания / В.В. Дрогомерецкий, А.А. Третьяков, Г.Л. Нестеренко, П.П. Кондратенко // Теория и практика физической культуры. - 2018. - № 7. - С. 39-41.

5. Морева В.0. 0 нарушениях опорно-двигательной системы челолвека /0.В. Морева // Бюл. медицинских интернет-конференций. -2014. - Т. 4, № 5. - С. 869.

6. Мосин И.В., Мосина И.Н., Есаулов М.Н., Царегородцева Л.Д. Использование фитбол-гимнастики на занятиях со студентами специальной медицинской группы, с заболеванием опорно-двигательного аппарата и нарушениями осанки в условиях технического вуза//Современные здоровьесберегающие технологии., МГГу.-Орехово-Зуево, -№2-2019.-С.90-102.

7. Мосин И.В., Мосина И.Н., Есаулов М.Н., Климаков А.В.// Использование циклических тренажеров нового поколения студентами специальной медицинской группы, с вегетососудистой дистонией//Современные здоровьесберегающие технологии., МГГУ--0рехово-Зуево,-№1-2020.-С.65-74.

8. Незлобина Е.А. Полная медицинская энциклопедия. М.;2011.-299с.

9. Симина Т.Е. Обучение плаванию студентов экономического вуза с использованием инновационных технологий // Scientific Discoveries: Proceedings of Articles the International Scientific N 345 Conference. - Czech Republic, Karlovy Vary : Skleněný Müstek - Russia, Kirov : MCNIP,

\footnotetext{
○ Мосин Игорь Васильевич (mosin59@mail.ru), Мосина Ирина Николаевна (trenermosina@yandex.ru),

Есаулов Михаил Николаевич (mesaulov@mail.ru), Петрушова Евгения Игоревна (happymosik@yandex.ru).
}

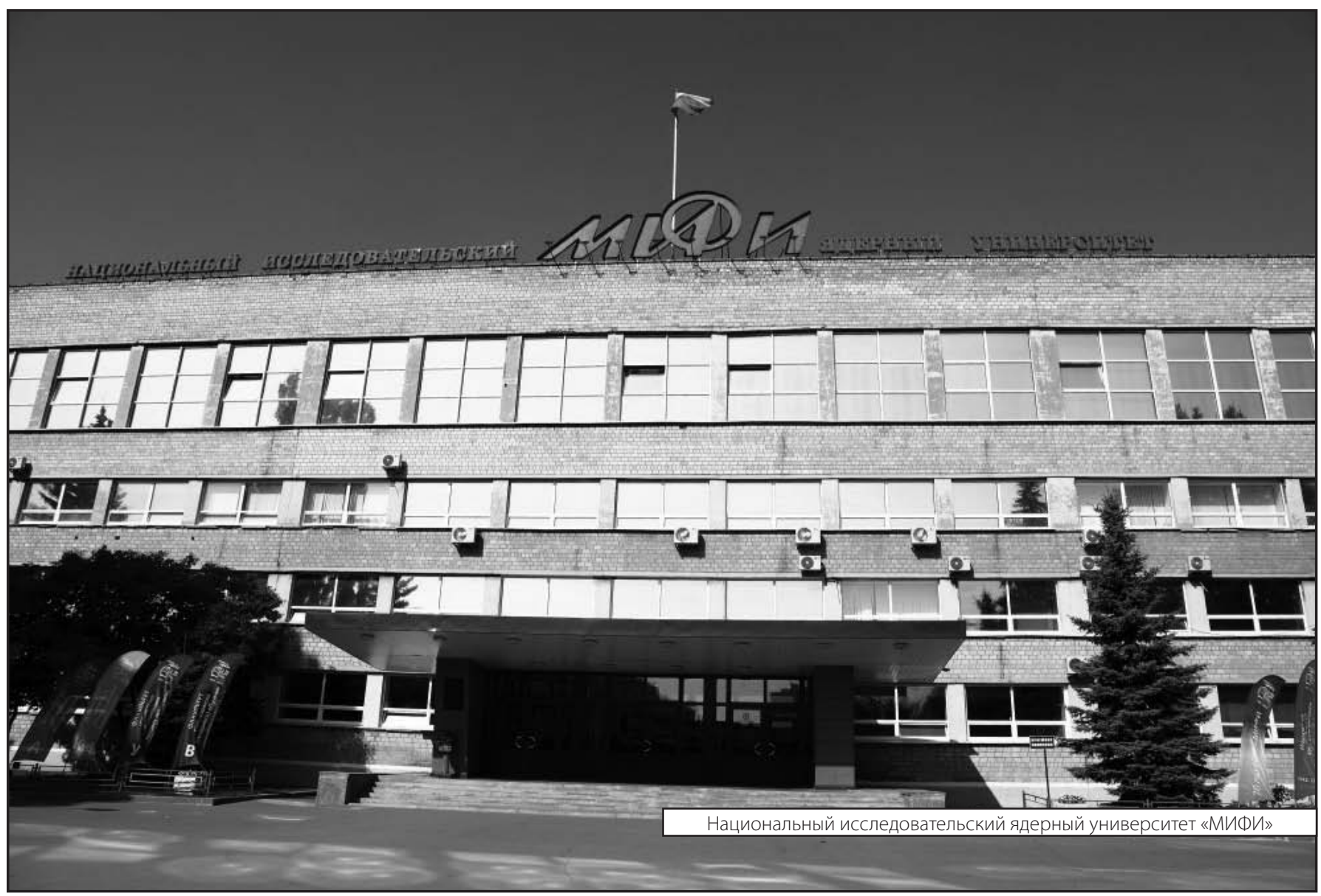

